Emotional Immersion Through Interactive Media

By

Shaun William Housden

Bachelor of Arts in Interactive Arts and Sciences

Brock University, 2017

\begin{abstract}
A MRP
presented to Ryerson University
\end{abstract}

in partial fulfillment of the

requirements for the degree of

Master of Digital Media

in the program of

Digital Media

Toronto, Ontario, Canada, 2018

CShaun William Housden, 2018 


\section{AUTHOR'S DECLARATION FOR ELECTRONIC SUBMISSION OF MRP}

I hereby declare that I am the sole author of this MRP. This is a true copy of the MRP, including any required final revisions.

I authorize Ryerson University to lend this MRP to other institutions or individuals for the purpose of scholarly research

I further authorize Ryerson University to reproduce this MRP by photocopying or by other means, in total or in part, at the request of other institutions or individuals for the purpose of scholarly research. I understand that my MRP may be made electronically available to the public. 


\title{
Emotional Immersion Through Interactive Media
}

Master of Digital Media, 2017

Shaun William Housden

Master of Digital Media, Ryerson University

\begin{abstract}
Using gameplay, video games immerse players into a variety of different emotional experiences such as excitement, fear and disgust. Other emotional experiences such as sadness, anger and happiness are generally relegated to be expressed by video and audio in games such as cutscenes and voice clips. The goal of this project is to create a game that uses its interactivity to make players feel immersed in emotions not usually found in gameplay. This will be done through the use of VR motion controllers and headsets to make the player feel immersed and more emotionally connected to their actions in the game.
\end{abstract}




\section{Acknowledgments}

I would like to thank all those who helped me in any way while doing both this MRP as well as my degree as a whole.

I would like to thank my parents for all their love and support through both my degrees, but specifically my masters as it would not had been possible without them.

The support of my friends as well as my MDM cohort (specially Jem) helped me get through the long months of development of this project and writing of this paper.

My girlfriend Kristy for being the person I needed to spitball ideas with and to especially help me with the rough early drafts of this paper.

To my supervisor Sheldon Rosen who not only assisted with helping to get to the core of my MRP, but also for helping me in the early months of this project when stress almost got the best of me. As well as my second reader Michael Bergmann for giving me critical feedback and believing and supporting in my idea for interactive emotional immersion.

And finally, to Justin Howe and Jason Hawreliak who guidance and teaching in my undergraduate degree helped me to realize that game development is what I want to do with my life. And without there assistance I would have never gained the skills I needed to complete this project. 
AUTHOR'S DECLARATION FOR ELECTRONIC SUBMISSION OF MRP............................. II ABSTRACT ..............................................................................................................................III

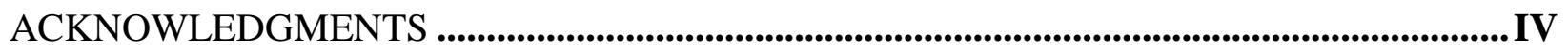

LIST OF ILLUSTRATIONS .................................................................................................. VI

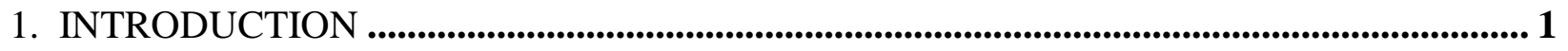

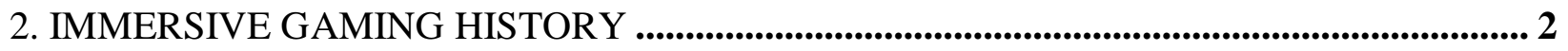

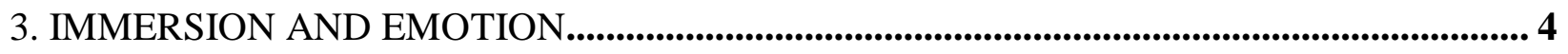

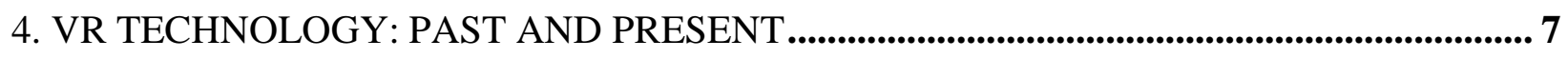

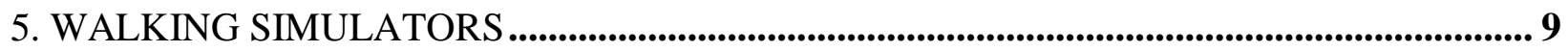

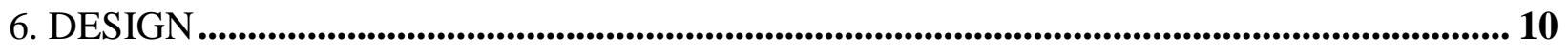

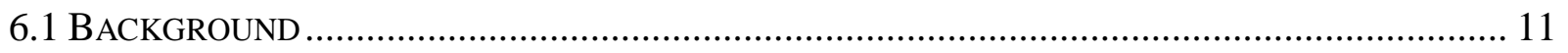

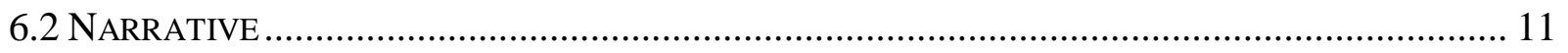

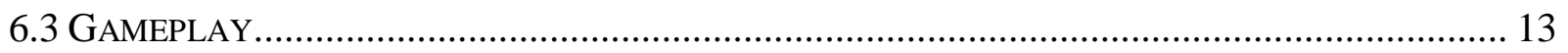

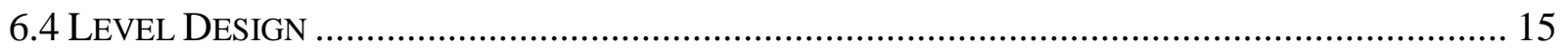

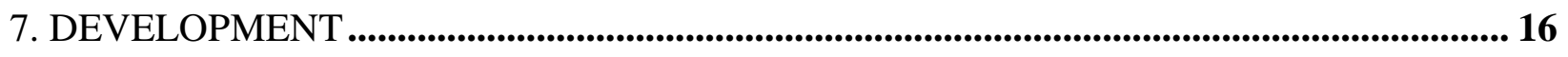

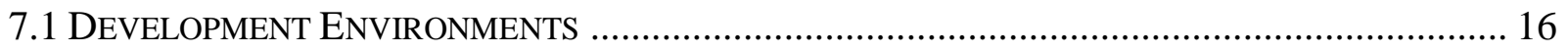

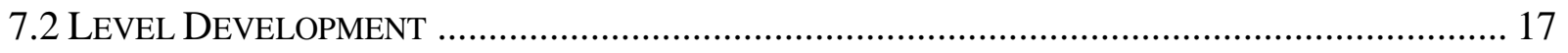

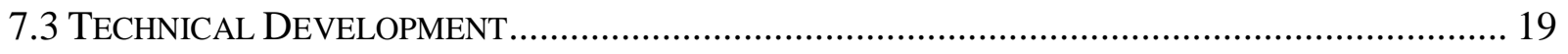

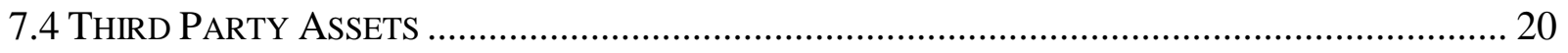

9. CONCLUSION .................................................................................................................................. 22

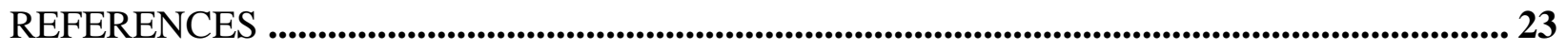




\section{List of Illustrations}

Figure 1. Top down screenshot of Apartment level in Unity game engine

Figure 2. Screenshot of the school featured in the School Memory level

Figure 3. Screenshot of Playmaker window with Basketball script open 


\section{Introduction}

Video games have always sought to allow people to escape their own lives in order to enter a world of fantasy. From the first video game created, Tennis for Two, people were able to escape from the stress of work at Brookhaven National Labs to the virtual tennis courts. In the 90's, millions of PC owners were able to free themselves of their safe suburban homes to the destitute and dangerous hallways of Doom where they were forced to fight against hordes of demons. Today, gamers are able to travel from the fantasy setting of World of Warcraft's Azeroth to the pixelated and puzzling world of Fez's Zu. Games open doorways into experiences and places that people would normally not get a chance to be a part of in the real world. Because of this, games usually attempt to express a certain feeling to a player, be it fear, disgust or surprise. These emotions are the most common, being the easiest to show through gameplay and direct interactivity. At the peak of these experiences is the idea of immersion. Immersion is defined as "deep mental involvement in something". It is in these game experiences that players have the most enthralling virtual experiences. However, the emotions of sadness, anger and happiness are not usually evoked through this gameplay interaction. They are instead shown using sound and video to the detriment of the immersive quality of the video game. This leads to a problem with video games, where certain games cannot generate fully realized emotional experiences in the medium they have chosen and thus, suffer in terms of quality of the overall experience.

While previous generations lacked proper ways to immerse players in feelings such as happiness, sadness or anger, modern advancements such as Virtual Reality (VR), have made experiencing such emotions easier using gameplay. Both VR headsets, which allow players to see through the eyes of their avatar, and VR controllers which allow players to virtually touch 
objects, allow them to more completely immerse themselves in the interactive experience by adding a real feeling of stepping into a virtual world. Therefore, it is the goal of this project to develop a VR game that focuses on immersing players through interactivity into emotional experiences such as sadness, happiness and anger.

\section{Immersive Gaming History}

Before turning to the development of this new immersive VR game, it is important to speak to the history of games and their development as experiences. While there are countless titles that have advanced the video game genre in this field of immersive experiences, four key titles are relevant here. These titles are: Space Invaders, Super Mario Bros, Doom and Grand Theft Auto 3.

The first title, Space Invaders, came out in arcades in 1978. Developed by Tiato, this "shoot 'em" up game allowed players to play as a laser cannon desperately defending earth from an army of slowly descending aliens. While far from being the first video game or even the first space related game, it was applauded for its quick gameplay and sense of urgency. Gamers

around the world, especially in Japan and the United States, couldn't get enough and by 1981 the various arcade cabinets around the world had grossed over 1 billion dollars (4 billion quarters) (Glinert, 1990, p321). When prompted as to why the game had done so well as compared to previous titles, Tiato's import manager S. Ikawa said "Space Invaders gives you a feeling of tension. A little neglect may breed great mischief' (Kent, 2001, p. 118). Space Invaders had led a charge of games that needed quick reflexes and great focus, leading to one of the first immersive titles on the market, but certainty not the last.

Next in this series of immersive games was Super Mario Bros which was released for the Nintendo Entertainment System in 1985. Players took control as a little Italian plumber named 
Mario as he speeds through the magical Mushroom Kingdom in an attempt to save the princess Toadstool (Peach). Unlike its arcade predecessors with single black screen "worlds", Super Mario featured a colourful sprawling world where players could go back and forth, popularizing the side-scrolling genre. This explosion in explorable space required an increase in activities to do, and so the game was filled with secrets to find. From warp pipes to new levels to bonus lives and power-ups, players found themselves in a game where they could spend countless hours exploring and become more immersed in this world.

Eventually the next jump in immersion development came in the form of Doom, which was made for MS-DOS based computers in 1993. Players took control of a rugged space marine and shoot through a demon infested research facility on Mars. Doom, like its predecessor, Super Mario, helped create a new genre of video games, "first person shooters" or FPS's. Players found themselves sitting behind the barrel of the guns they held as if the computer itself was a window into this world. As well, players didn't jaunt along at a slow pace, they accelerated at high speeds, running through the hallways of the facility and blasting away at demons at every corner. To top all of this off, Doom felt real; its levels simulated real places players could find, with walls and structures at different angles compared to the straight 90-degree walls of previous generations. Those walls as well weren't just solid colours, they were actually textured making every corner of the world feel as if you could reach out and touch it (Kushner, 2004, p.130). An unknown critic for the Arizona Republic in 1994 had this to say about the importance of Doom: "This game is so intense, and so genuinely frightening that the deeper you venture into these shadowy chambers the closer your nose gets to the screen - an indication, I believe, of how much you, the player, enter this adventures game’s other reality.” (Kushner, 2004, p.161) 
Finally, there came Grand Theft Auto 3 for PlayStation 2 in 2001. Here, players took control of a recent escaped felon who's given free reign of a city filled with crime and corruption. GTA 3 had many of its forbearers' immersive traits. It had a large world and it looked realistic, but it had one improvement - pure freedom. In Grand Theft Auto players could travel anywhere they wished to any portion of the map with no restrictions. The game wasn't cut into levels like previous games, it was a whole living, breathing world with no loading times while scouring the city. With this advancement, players no longer felt disconnected from the game as they waited it to load or felt held down by the game. For the first time, players had absolute freedom to do whatever they wanted. Founder of Insomniac Games, Ted Price put it best when he described how he felt the first time he saw the game in action "Wow. You can do that? And wait, you can do that? Holy cow, how are they doing that?" (Price, 2001).

These four titles had a ground-breaking impact not only on the medium of video games, but also on how they could be immersive experiences. While it's been stated what specific features made these games immersive, it's still fundamental to understand what it means for something to be an immersive experience. This leads into the importance of what immersion means when creating an emotional experience for a player.

\section{Immersion and Emotion}

While there are many definitions and ways to explain immersion, the most straightforward comparison is to someone who has gone swimming. The water the person finds himself in is the video game they are currently playing. While not all games are completely immersive, they all have a certain degree of immersion, like a person wading in a pool. As players get deeper into the water and become more submerged, they become more immersed. Finally, they are completely under the water and totally surrounded by this new world they find 
themselves in. However, like the person coming up to the surface for air, immersive experiences will end.

Immersion is generally the term specifically used for video games while other terms have been used for other technologies. Presence, for example, is a term coined to describe a similar feeling in virtual environments and is defined as "as the subjective experience of being in one place or environment, even when one is physically situated in another" (Ephraim, 1990). An immersive experience involves a lot of different features, but overall there are three key considerations to test if a game is immersive: First, the player begins to lose their sense of time in the real world. Secondly, the player will begin to lose awareness of the real world around them i.e., real world stimuli such as sound and light. And finally, the player will feel a sense of direct involvement with the task they are undertaking in the virtual environment (Jennett et al, 2006). All three of these key features of immersion do not necessarily occur at the same time. Immersion has different levels or states which allow for the previously stated features to occur. The lowest level of immersion is engagement. This is relatively easy; all that players require to be engaged is effort and attention to whatever game they are playing. The hardest part of this process is the passion to play the game they have chosen. If a player lacks an interest in a certain genre or style of game, then it will be impossible for them to start feeling engaged. The next level of immersion is engrossment. This is the first stage that involves an emotional connection between the players and game. Players will begin to feel this if the different aspects of the game begin to come together and created a unified experience. When aspects, such as good level design, clear and tight controls and interesting characters come together they begin to enthrall a player more. It is at this stage that like previously stated players begin to 1. Lose sense of time in 
the real world and, 2. Lose awareness of the real world. Lastly, there is total immersion. This stage is defined by its feeling of the player being completely disengaged from the real world in favour of the virtual world. In this stage the only two barriers to being total immersed are atmosphere and empathy. Atmosphere involves the systems and look of the game coming together to develop an enthralling game world. Empathy involves the player feeling a personal connection to the character in the game, in a sense it is considered a "transfer of consciousness" (Brown \& Cairns, 2004).

Empathy is crucial in a player's total immersion into a game. Thus, it seems appropriate to address the direct connection between emotion and immersion. Cesar Ojeda (2007) states that having emotional attachment between both player and game is key to developing immersion. There are two theories of connection between emotion and immersion. The first is that the connection of the two elements occurs due to the choice that a player must make in the game they are playing. This claims a connection between what that choice represents to that individual in that point in time. The second is that an immersive environment in a game connects a player's senses to the avatar they inhabit within the game. With this connection made, players feel an emotional, almost physical connection between themselves and the game (Mendonça \& Mustaro, 2012). Beyond theories of connection, there are certain methods that have been proven to connect a player to an avatar causing complete immersion. One is creating characters that players will connect with emotionally, due to a similar background or beliefs. While this method is effective it may not be very good for interactive emotional immersion, unless players have a choice to create their own characters like in Role Playing games, then this connection is purely through narrative. The second option is by creating scenarios that emotionally affect the players 
and characters. This method is more in line with an interactive experience because it allows for greater choice and interactive moments as compared to the previous method (Freeman, 2004).

While immersion and its connection to emotion are the key aspects to this project, it is important to note that traditional video games played in front of a screen can only rarely allow a player to become entirely emotionally immersed with an image on a screen. Thus, one of the most important features of this study on emotional immersion is the method in which players are actually entering the world of the game: VR.

\section{VR Technology: Past and Present}

While it would be wrong to say that video games led directly to the invention of Virtual Reality, they do have a long history of cohabitation with one another when it comes to innovation. The very first commercial VR, Sword of Damacles, was created in 1968 by Ivan Sutherland. While not a game in any sense, it was the first real implementation of head tracking to look around a 3D rendered environment for the commercial sector (Jensen, 2016). Beyond Sutherlands first try, were the first real attempts at some sort of video game related VR in the 1980's and 1990's. Major video game developers such as Sega, Nintendo and Atari all had attempts at either adding VR peripherals to their already existing systems or creating entirely new platforms to try out VR games for the first time. Unsurprising, this technology failed to sell well enough to be called anything close to VR. Nintendo's try at the market with their failed Virtual Boy console was unsuccessful for a number of reasons including an exclusive colour pallet of red and black and terrible portability for a "portable" system (Edwards, 2015). Sega's multiple attempts such as the Segascope 3-D and Sega VR, either weren't real VR or were abruptly cancelled (Jensen, 2016). After almost two decades of failed VR attempts by major companies it seemed it just wasn't in the cards for VR games to become a commercial success. 
In the two decades following the commercial failure of video games as a VR platform, most virtual reality experiences were limited to large and expensive arcade games. Large and expensive seemed to be factor stopping VR from breaking the commercial ceiling and a lack of developer interest outside of last minute conversions to VR. In the early 2010's, the commercial success of both the Oculus Rift and the HTC Vive were the first successes of VR as a gaming platform. Both systems incorporated high quality HD headsets that allowed for players to go into the virtual worlds they had been clamoring to be a part of for decades. As well as headsets, both VR systems included controls featuring traditional button controls as well as motion controls. Oculus became popular with developers for its lower end price and its easy access very early in its development (Kumparak, 2014). And Vive found its success due to video game developers Valve Corporations early interest in the project and its easy integration into their video game distribution system Steam (Souppouris, 2016).

The new generation of VR didn't just do well because of good partnerships and advanced technology though, it was finally able to allow players an opportunity to become more connected to their virtual worlds. One major leap towards improving the immersive experience with VR was the inclusion of controllers with motion controls integrated technology. Now, instead of a player looking around with their headset while holding a normal controller, they had the ability to reach around their environment and feel as if their hands were also part of this world. A study by Mattias Nässén (2014), was done to compare various controllers and the effect they had on the immersive experience for players. Both traditional controllers (an Xbox 360 Controller) and motion controllers (a PlayStation Move), were utilized in the experiment. Players were given a game to try out various actions. In the end Nässén discovered that almost $90 \%$ of participants found the motion control to make their experience more immersive. Participants commented that 
actually reaching for objects and leaning to get them made the whole experience much more natural and immersive (Nässén, 2014).

VR's impressive advancements in the last half decade have shown that immersive experiences can be more easily developed with the use of its technology. By using headsets to put players into their virtual worlds and giving them motion controllers to reach out and grab it, it becomes easier to develop games that have certain emotional immersion. This unfortunately has not occurred in recent years. Instead a new genre of games has appeared to assist in generating emotional experiences such as sadness, anger and happiness. This is the genre of "Walking Simulators".

\section{Walking Simulators}

The term "Walking Simulator" has always been and currently still is a hotly debated term in the video game community. Most would place many games into the genre as a way of quickly categorizing games that generally don't follow traditional genre rules. Games like Call of Duty or even Super Mario Bros are easily characterized. In Call of Duty you shoot, so it's a shooter, and in Super Mario you jump and avoided obstacles, so it's a platformer. But games such as The Stanley Parable and Firewatch are much harder to categorize. Most can agree that "Walking Simulators" are games that heavily stress narrative and exploration. While most other game genres involve gameplay as their main draws, these games focus more on telling a story in a virtual environment. These stories are usually pushed towards the emotional experiences that aren't favoured by the more gameplay focused genres, such as sadness, happiness and anger (Clark, 2017). Before discussing the negatives of the genre, it seems best to state that the goal of this paper is to not belittle the genre of "Walking Simulators". In fact, the purpose of this paper is the opposite as it is a celebration of what games are capable of doing of as an art form. The way 
that "Walking Simulators" choose to achieve immersion and emotional responses from its players is a choice like any other. Unfortunately, many games choose to use narrative, audio and visuals over direct gameplay to make players feel certain emotions.

"Walking Simulators" are games that generally involve as little interaction as moving the player character from one space to another. The emotional response or immersive qualities come not so much from doing something in gameplay as it does from hearing or watching something unfold in front of the player. Some games in this genre do have more choice within them, such as picking what characters will say such as in Oxenfree or having puzzle elements such as in Ether One. However, most "Walking Simulators" try to get across their elements by using narrative. Therefore, the game development community debates the use of the word "Walking Simulator" as it is generally seen in a negative light. Games in this genre aren't always thought of as actual games, as they don't have interaction outside of movement. Developers find this belittling to their work, as it constricts the definition of what is a game. Other developers say that "Walking Simulator" is an attempt to keep out independent developers from creating titles that will be considered games. With smaller budgets and teams compared to major AAA developers, games like "Walking Simulators" are the only kind of games they can create ("Stop using the term", 2016).

These issues with "Walking Simulators" make it imperative to prove that a game can be created that allows for deeper emotional connections inside gameplay. This paper will discuss the design and development of this new VR game, focusing specifically on generating an immersive emotional experience.

\section{Design}




\subsection{Background}

The design process for this project began with the development of a previous project for the graduate level class DG8010: New Frontiers (AR/VR in practice). This class was tasked with creating a final VR/AR assignment. The outline was open allowing for freedom in design. I chose to develop a VR game as that was the intended focus of my MRP. This allowed for me to practice my skills in VR game development. The game developed in this project focused on giving the player immersive feelings of sadness. It was appropriately called "Project Sadness" and became my inspiration for focussing on more emotions than sadness. In the game, players could take control of a child whose parents have decided to divorce. Each "level" was a vignette of different important stages in this upsetting event. The game begins with the player confronting his or her parents in their apartment kitchen as they fight in the middle of the night. The player slowly progresses through having to move out of their home and choosing a parent to stay with. The goal with this project was see if, by giving players direct interaction with an emotional experience it would bring about those emotions tied to the divorce of one's parents. Having to pick and choose what personal items to keep and throw away when moving to seemingly unemotional things such as turning off the lights of the family home for the last time. While the project didn't come out quite as immersive as I would have wanted it to be, it did give me a sense of what do for my final MRP version.

\subsection{Narrative}

While this project is based on the idea of making people feel emotionally immersed through their physical actions in the game, it also was inspired by one thought I had a few months before development of the game started. This idea was the importance that physical objects have to people. The importance of these objects isn't the same as a cross is symbolic to 
Christians or why the United States flag has importance to an American. Everyday objects carry more emotional weight for one person than another. People form connections to items that allow them to connect to a memory involving the physical object. Thus, the motivation for this final MRP is to create a game surrounding certain objects that will take the player to important places, or memories, that these items represent.

I decided to develop a narrative that would support the idea of interactive emotional immersion. Initially, I began with the idea that the only emotion I would focus on would be sadness. With this framework, I brainstormed sad situations that would be universally understood, to make the game immersive to as many people as possible. Concepts such as the destruction of family and death became the most apparent because of their universal nature. I had chosen destruction of the family for my previous VR assignment and even considered doing it again, however I decided against it, as I didn't wish to repeat myself. Therefore, I followed death as the starting concept for my games narrative, as it is universal since everyone will have to deal with death in their lifetime. I chose to use this in combination with the human attachment to physical objects in the form of memories. When visiting a home for the first time, it is typical to question the objects people choose to keep and display. Therefore, I decided to develop my game around a person having to organize the possessions of a loved one.

With a baseline narrative, I decided that making players feel a certain way about death would be challenging. That while the emotional focus was sadness, it remains for the players to form their own emotional responses. I considered changing the plot altogether, but it is impossible to make any crafted narrative inherently sad. I decided to stick with my original story, finding that even if I couldn't control what emotions the player could feel it was still going to be a game where players could find happiness, anger or sadness in their surroundings. 
I did not wish to make the story involve other human characters physically, as seeing virtually crafted people would draw away from the immersive reality of the game. I wanted to make the experience a solitary one. Thus, I choose to make the game about an individual dealing with the last wishes of his or her recently deceased friend. In the game, players are sent to their friend's apartment where they had been left a list of final wishes to be completed. Initially I designed the game to be very story focused from the start, involving a voice over of a note left by the deceased. It would have made the story more forward and easier to understand but there was one problem - this choice takes away from the players' ability to interact with the game and feel independent emotions. Therefore, I removed portions of the design that directly led a player somewhere and instead chose to let them find the story on their own. Instead of conventional storytelling through dialogue or writing, it was to be found in the world they had walked into. I wanted to use the levels as a place to put items that would tell you more about the loved one who had passed away.

\subsection{Gameplay}

The most important part of this project comes down to the gameplay. How can players feel these emotions through the interactivity and their own actions? Making someone feel sad, happy or angry from doing something is very difficult. However, some basic interactions can inspire very basic emotions. One of the first actions I thought about was opening a door. This doesn't generally have any emotional connotations. Thinking about what a door could represent brings about more emotional meaning. Closing a door can meaning starting something new which is a happy feeling, or it could mean closing something off which could be sad. Even at its core, opening a door gives a feeling of wonder and surprise about what could be behind it. So, I 
decided that game would involve moving from one room to another and forcing players to open these doors physically with the motion controls given.

Second, was the list of last wishes by the player's deceased friend. This is the main instruction given to players. The list presents tasks that they could interact with to make them feel immersed in their characters emotions. I used myself as a model for what someone's last wishes may be. Generally, chores would need to be completed. From my previous project "Project Sadness" I found that the action of placing objects or throwing them away had a strong emotional connection, like closing a door it could mean the end of something or beginning of something new. I formed two separate ideas of tasks. First, was the idea of putting textbooks into a box for donation. This action allows for players to see the effects of this death and allows them to look at these items more closely and try to understand their significance to the deceased. Second, was the idea of dirty plates being placed around the apartment and having to put them into the sink to be cleaned. This adds an element of history to the action showing that the deceased was a dirty person, but by placing them around the apartment it also allows the player to search and discover more about the apartment.

Thirdly, I thought about the concept of what marks left by those who have died, like a handprint left on a window. This sort of idea of destroying or changing what is left by a loved one is quite an emotional thought to think about, would a person want to get rid of something that stands between themselves and fully losing their loved one? While this thought was sad in nature, I also began to think about the positive ways interacting with a loved one for the last time could be and so it helped lead me to another interactive element of the game. In the apartment, players come across a toy basketball net in the living room with an LED scoreboard. Players are able to pick up a toy basketball and toss it into the hoop gaining points for each successful point 
they score in the time limit. The goal is to make it feel as though the player is playing one last game with their loved one if they are able to beat the high score left by the deceased though that removes a "mark" they left on the world, so it becomes an emotional decision whether to do so.

The next two items on the list involve less physical interaction, but still gives the players a sense of immersion. First was a record player. Players in the living room of the apartment will find a record player with three records beside it. Players are able to pick up any of the records and play the record. Each would play a song that represents a different style of song, for happiness, sadness or anger. With this, players are able to further immerse themselves in the experience they are having. Finally, I found myself considering an interactive element that was actually quite emotional from the offset. The idea was based on the Jewish tradition of Shiva, the mourning period of a loved one. Players have to go to the mirrors of the apartment and cover them up with blankets. This not only made the players again remember the death of the player characters friend, but also added to the background and story of the deceased.

Lastly, I turned to my original idea and how they would form connections between the objects and memories. Using audio or other characters to generate these memories would be too strongly leading the player to think any one way, thus, I decided to create memories to send the player to. Once players had finished these tasks connected to the item they would be transported to the location of the memory. For the textbook I decided on the memory on the first day of university, for the dishes a memory of leaving home and for the mirror a memory of past loss at a hospital.

\subsection{Level Design}

The game is comprised of 4 different levels. The apartment is the main hub of the game and the 3 memory levels. The apartment hub is comprised of a hallway featuring the main 
apartment, an extra empty apartment and a supply closet. Players begin the game in an elevator at the end of the hallway and upon moving forward the doors will open revealing the main hallway. The apartment is made up of a living room, kitchen, bathroom and bedroom. As I stated before, the environment is be used for players to pick up narrative information. Items such as a Yankees jersey, keyboard and game system fill the apartment giving the idea of what type of person may have lived there.

For the memory levels, each follows a similar style separate from the look of the main apartment hub to give players a sense of dream like wonder. While the apartment looks real featuring various textures for each object, the memory levels lack that. Instead they have a colour palette of whites and creams to make them feel as if they were distant memories. Certain objects contain colour or texture such as red tail lights of a car or the dark blue of a hallway sign. These

objects have specific colour detail due to the random nature of memory, where certain features of a memory are stronger than others. Players begin seemingly floating in air and see in the distance the memory. They approach the memory and as they got closer a sound connecting to that memory plays. The university memory has a set of library steps leading up to large stone columns and as players approached they hear the sound of students talking and rushing around. In the moving away memory, players find themselves standing outside a childhood home as a car sat out front, the sound of its engine running and waiting. Finally, in the hospital memory, players come across a hospital hallway and after entering, slowly hear the sound of life support machines as they approach one particular room.

\section{Development}

\subsection{Development Environments}


The game was developed using Unity 2017.3 as its main engine. All 3D models were created with the use of Autodesk Maya. All textures were created in Adobe Photoshop and for more detailed textures including those with writing, Adobe Illustrator was used. For any audio segments that were made, or edited Audacity was used. Finally, an HTC Vive was used as the main control input for the project including its headset and two controllers.

\subsection{Level Development}

The creation of each level began with the same process of sketching out the environment with Probuilder. Probuilder is a Unity plugin that allows for the quick creation of building materials for environments such as stairs, walls and doorways. Using this, the environments were sketched out in Unity usually using square walls and floors to get a quick idea of what the environments may look like. After walking around the level and finding it to be the right size, the walls were rebuilt to the specifications of that exact level.

Each level had different specifications to be followed to make the layout realistic. First, the apartment level includes a main hallway, apartment, an empty apartment and supply closet. All of these rooms include textured floors, walls and ceilings that were all created in Photoshop. The supply closet is 3D modeled with shelves, mops, buckets and paint cans that were created with Autodesk Maya. The apartment includes a bedroom, kitchen, living room and bathroom that are also filled with 3D modeled objects that make the environments seemed lived in. At the end of the apartment hallway is an elevator that was $3 \mathrm{~d}$ modeled. 


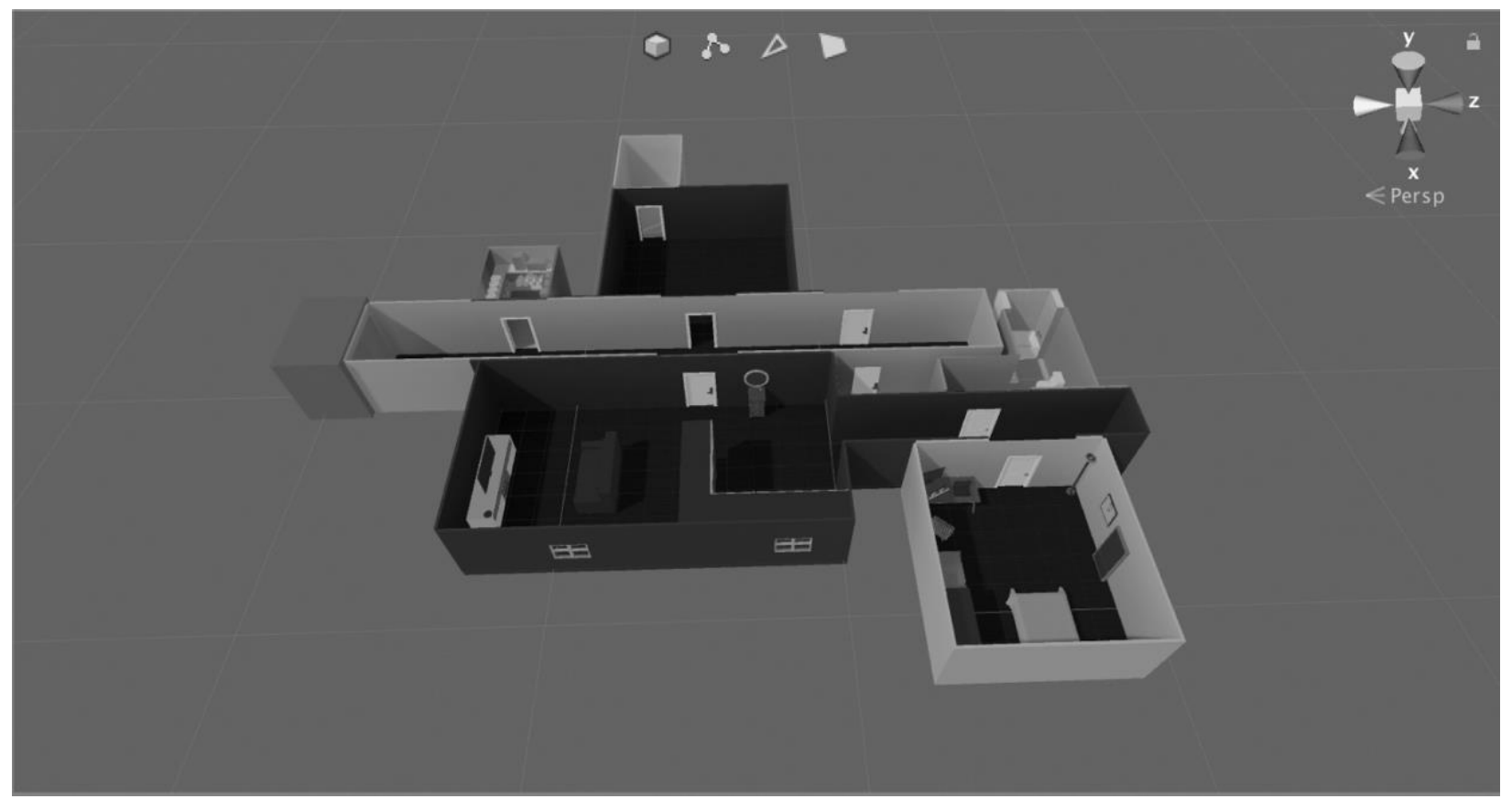

Figure 1. Top down screenshot of Apartment level in Unity game engine

Memory levels are constructed similarly to the apartment level, but with a greater focus towards playmaker for 3D modeling rather than Autodesk Maya. In the school memory the main building steps and walls were created with Probuilder and the handrail and columns were created using Maya. The sound of students on a quad was recorded at the University of Toronto Mississauga in a public area and edited using Audacity. In the house memory, the home itself and the fence were created with Probuilder and the car as well as the details on the house were made in Maya. The sound of a car running was recorded from a Ford F-150 truck and was later edited in Audacity. Finally, the hospital memory had its hallways and hallway details created in Probuilder and the hospital bed and signs were made in Maya. The sound of hospital beeping was recorded in a McDonald's and edited in Audacity. Any of the texture in the memory levels was produced in Photoshop. 


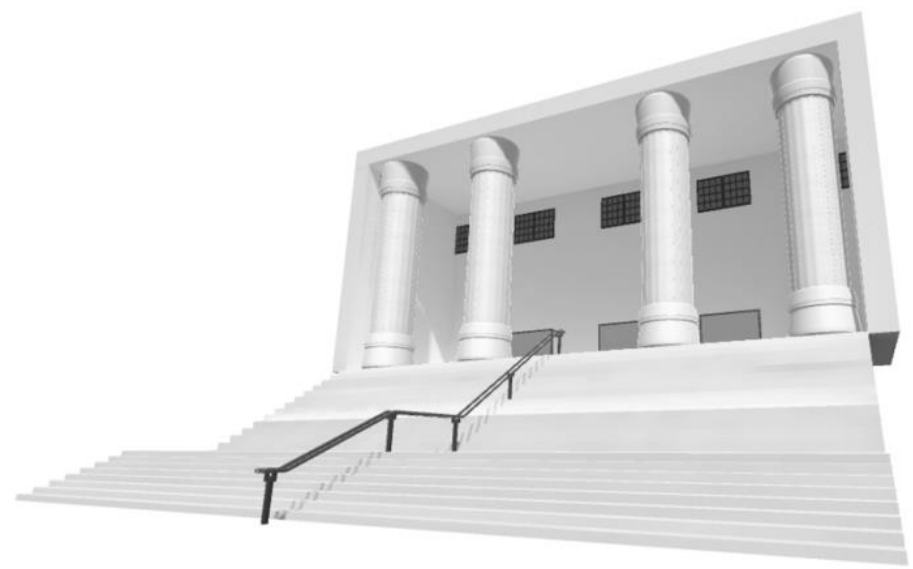

Figure 2. Screenshot of the school featured in the School Memory level

\subsection{Technical Development}

The technical aspects of the project were created with the assistance of VRTK and Playmaker. Playmaker is a Unity plugin that allows developers to visually script as compared to writing the scripts directly. VRTK is another plugin for Unity that helps with the development of VR games by supplying scripts for many basic functions. VRTK assisted the project with many things including the following:

- Tracking the Vive Headset as an in-game camera

- Tracking the Vive Controllers in-game

- Using the Vive Controllers trackpads for player movement

- Highlighting certain objects to show interaction points

- Picking up objects with the Vive controllers

- Using Vive controllers to open doors

Playmaker was helpful to script certain in game events to occur such as sounds, level changes and movement of objects. The following are the things that Playmaker assisted with the scripting of: 
- Opening the elevator to players in the Apartment level

- Playing music on the record player in living room

- Triggering events after certain items touch (ie. Plates in rack and books in box)

- Transporting the player to various memory levels (ie. House, School and Hospital Levels)

- Transporting the player back to the apartment level after reaching certain spots

- Making the deceases will pop in the UI for better readability for the player

- Updating score visually and in memory on the basketball game in living room

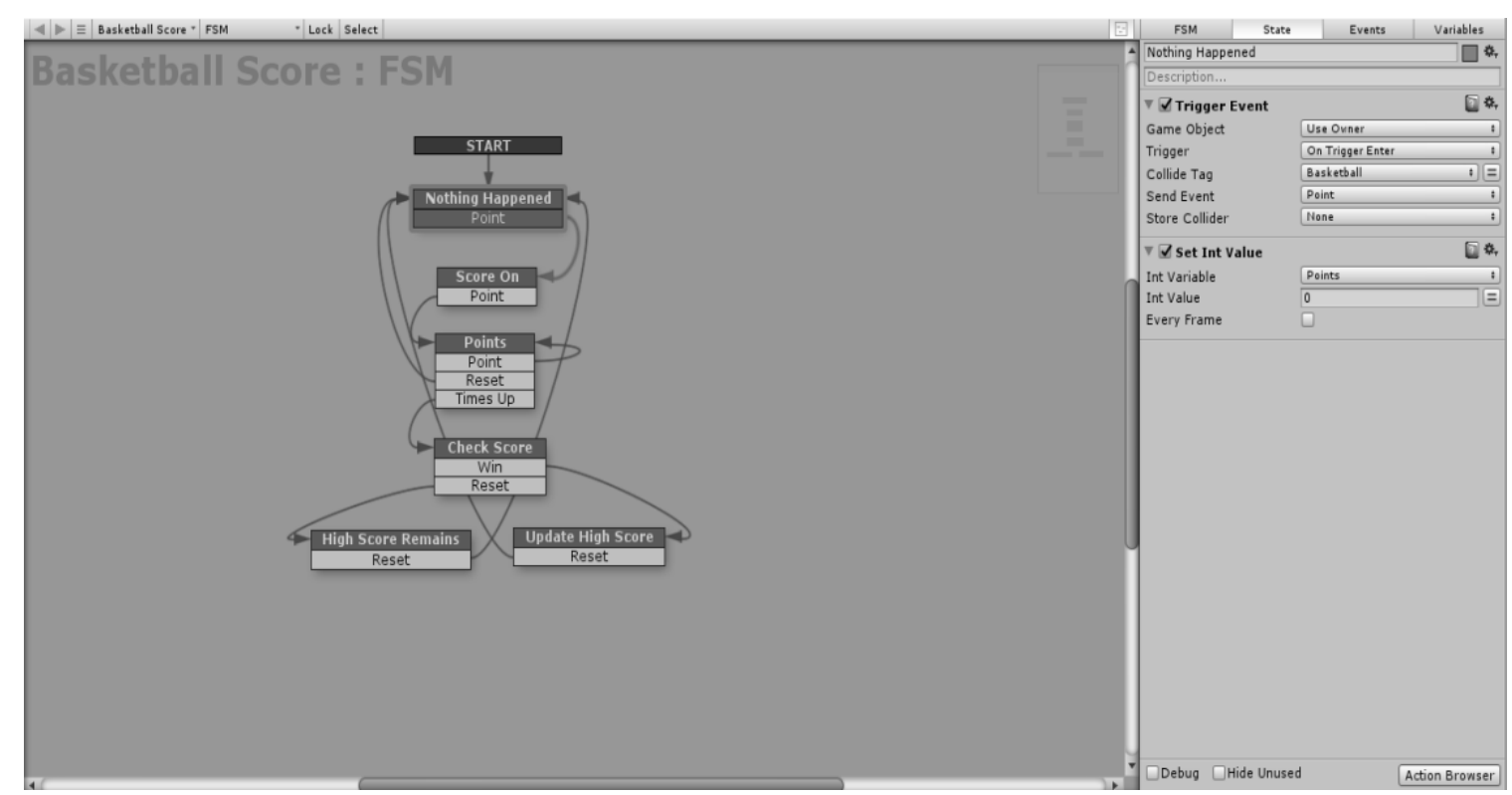

Figure 3. Screenshot of Playmaker window with Basketball script open

\subsection{Third Party Assets}

The goal of this project was to create all necessary aspects of the project from scratch to help myself with understanding the workflow and creation process for each part. While the majority of the project was still created by myself from scratch, some aspects towards the end of the development required me to find other sources to speed up the process and get certain aspects of the project completed in time for the final poster presentation. Thankfully most of the content procured from other sources mostly came down to sound effects and music that could not be 
easily created or recorded me. All music featured on the record player in the living room was found on Freemusicarchive.org and came from four different artists. The four songs are Western Tanager by Chad Crouch, All The Colours In The World by Podington Bear, Western Shores by Phillipp Weigl and Song 6 by The Austerity Program. All songs featured in the project fall under a license allowing for free usage on artistic projects that are non-commercial in nature. Next, the sound effects in the game when a memory level object is picked up were all found and sourced from various YouTube based sound libraries for amateur film productions. These sounds included a chalkboard being written on for the school memory level, a car driving over a rocky driveway for the moving away memory level and shoes squeaking on a floor for the hospital memory level. Finally, the only non-audio asset sourced from a third party was the font used for the will found in the game featuring the list of interactive options in the game. The use of a handwritten note style necessitated a hand-written font and so one was procured called Gunny Rewritten from dafont.com.

\section{Future Steps}

The successful completion of the vertical slice of this game does not mean that it is completely done. On the contrary, the point of this project is to test and prove that emotional immersion can be caused through interaction over other non-interactive elements. While this game holds many of the aspects that it was originally designed to have, there are improvements and changes that could be made in future iterations of the project. First and most obvious is to increase the number of interactive elements such as those tasks left by the deceased. Some other tasks were devised but never implemented such as looking after an animal that was left behind. These points would not all be directly connected to memory levels, but perhaps would be placed in the game to further the narrative aspect of the game. The next improvement would have to do 
with the size and density of the levels. While the current levels are big for a vertical slice, with an increased amount of interaction in the game, an increase of size for the levels would also be required. With an increase in the size of the environments, they would have to be filled with more objects that are non-interactive such as furniture in the apartment level. Finally, there is the addition of more choice and customization for the player. Like stated earlier in this paper, a greater connection to one's avatar creates a greater emotional connection and helps with immersion. Because of this, more direct choices in the game could help with immersive qualities of the game even more.

\section{Conclusion}

In conclusion, the goal of this project is to create a VR game that enabled emotional immersion through interactivity rather than narrative elements. Emotions such as anger, sadness and happiness are generally triggered in a player through narrative and so these emotions were focused on as the immersive quality for the player. This was done with the assistance of both a VR headset and controllers that allowed players the ability to feel more closely connected and immersed in their experience. The game itself was produced with the assistance of the Unity game engine as well as VRTK, Playmaker, Probuilder, Photoshop, Illustrator and Audacity. Future development will be focused on increasing the number of interactive elements and size of the game from a vertical slice to a full experience. 


\section{References}

Cairns,P.,Brown,E. (2004) A Grounded Investigation of Game Immersion. UCL Interaction Centre. Retrieved July 20, 2018 from http://complexworld.pbworks.com/f/Brown+and+Cairns+(2004).pdf.

Cairns, P., Cox, A., Berthouze, N., Dhoparee, S., \& Jennett, C. (2006). Quantifying the experience of immersion in games. UCL Interaction Centre. Retrieved July 20, 2018, from https://pdfs.semanticscholar.org/781a/5ee600063c36fd5526fbba85a28bce323c5b.pdf.

Clark, N. (2017, November 12). A brief history of the "walking simulator," gaming's most detested genre. Retrieved July 23, 2018, from https://www.salon.com/2017/11/11/a-briefhistory-of-the-walking-simulator-gamings-most-detested-genre/

Edwards, B. (2015, August 21). Unraveling The Enigma Of Nintendo's Virtual Boy, 20 Years Later. Retrieved July 21, 2018, from https://www.fastcompany.com/3050016/unravelingthe-enigma-of-nintendos-virtual-boy-20-years-later

Ephraim, G. P. (1990). Visual Programming Environments: Applications and Issues. IEEE Computer Society Press, 1, 321. Retrieved July 18, 2018, from https://books.google.ca/books?id=NMtWAAAAMAAJ\&q=Visual Programming Environments: Applications and Issues\&dq=Visual Programming Environments: Applications and Issues\&hl=en\&sa=X\&ved=0ahUKEwi347yA6qncAhXGA4gKHZsyD_4Q6AEIJzAA.

Freeman, D. (2004). Creating Emotion in Games: The Craft and Art of Emotioneering. Computers in Entertainment,2(3), 15. doi:10.1145/1027154.1027179

Jensen, K. T. (2016, April 15). The history of virtual reality video games. Retrieved July 21, 2018, from https://www.geek.com/news/the-history-of-virtual-reality-games-1652225/

Kent, S. L. (2001). The Ultimate History Of Video Games. New York: Three River Press.

Kumparak, G. (2014, March 26). A Brief History Of Oculus. Retrieved July 21, 2018, from https://techcrunch.com/2014/03/26/a-brief-history-of-oculus/

Kushner, D. S. (2004). Masters of Doom: How Two Guys Created An Empire And Transformed Pop Culture. New York: Random House.

Marks, R. B. (2016, August 18). The Most Important PC Games of all Time: Doom. Retrieved July 18, 2018, from https://www.pcgamesn.com/most-important-pc-games-doom

Mendonça, R. L., \& Mustaro, P. N. (2012). Immertion: Immersion and Emotion in Digital Games. Universidade Presbiteriana Mackenzie. Retrieved July 20, 2018, from https://pdfs.semanticscholar.org/eb2f/847dfab7339bd575c6cb2aa71c3a7498340f.pdf 
Nässén, M. (2014). Motion controls in a first person game: A comparative user study using various input methods(Unpublished bachelor's thesis). Blekinge Institute of Technology. Retrieved July 23, 2018, from https://www.divaportal.org/smash/get/diva2:831176/FULLTEXT01.pdf

Ojeda, C. M. (2007). In The Game : An Exploration of the Concept of Immersion in VideoGames and its Usage in Game Design(Unpublished masters's thesis). Edith Cowan University. Retrieved July 20, 2018, from http://ro.ecu.edu.au/cgi/viewcontent.cgi?article=2297\&context=theses_hons

Souppouris, A. (2016, March 18). How HTC and Valve built the Vive. Retrieved July 21, 2018, from https://www.engadget.com/2016/03/18/htc-vive-an-oral-history/

Thomsen, M. (2011, October 17). The Game Industry Remembers Grand Theft Auto III. Retrieved July 18, 2018, from http://ca.ign.com/articles/2011/10/17/the-game-industryremembers-grand-theft-auto-iii

Is it time to stop using the term "walking simulator"? (2016, October 06). Retrieved July 23, 2018, from https://killscreen.com/articles/time-stop-using-term-walking-simulator/ 